\title{
A Two-Step Flow of Influence?
}

\section{Opinion-Leader Campaigns on Climate Change}

\author{
Matthew C. Nisbet \\ American University, Washington, DC \\ John E. Kotcher \\ National Academies, Washington, DC
}

In this article, we review concepts, measures, and strategies that can be applied to opinion-leader campaigns on climate change. These campaigns can be used to catalyze wider political engagement on the issue and to promote sustainable consumer choices and behaviors. From past research, we outline six relevant categories of self-designated opinion-leaders, detailing issues related to identification, recruitment, training, message development, and coordination. We additionally analyze as prominent initiatives Al Gore's The Climate Project and his more recent We campaign, which combines the recruitment of digital opinion-leaders with traditional media strategies. In evaluating digital opinion-leader campaigns, we conclude that there are likely to be significant trade-offs in comparison to face-to-face initiatives. The challenge for both scholars and practitioners is to understand under what conditions are digital opinion-leaders effective and in which ways can online interactions strengthen or build on real-world connections.

Keywords: opinion leaders; influentials; climate change; framing; digital networks

W

hen it comes to catalyzing collective action on climate change, opinion leaders remain an overlooked yet necessary resource. Until only very recently, public communication initiatives have ignored the special

\footnotetext{
Authors' Note: This article was supported in part by a faculty grant to the first author from the Provost's office at American University, Washington, DC. Direct all correspondence to Matthew C. Nisbet, School of Communication, American University, 4400 Massachusetts Avenue NW, Washington, DC 20016; e-mail: nisbet@american.edu.
} 
individuals across communities and social groups that can serve as vital go-betweens and information brokers, passing on messages about climate change and energy conservation that speak directly to their otherwise inattentive peers, coworkers, and friends. Since as early as the 1940s, scholars have understood the general importance of opinion leaders in shaping public preferences, informing fellow citizens, and altering behavior. Tracing the diffusion of news and advertising messages within local communities, Paul Lazarsfeld, Elihu Katz, and colleagues (1948) identified certain individuals who paid close attention to an issue, frequently discussed the issue, and considered themselves more persuasive in convincing others to adopt an opinion or course of action. In this two step-flow of information, opinion leaders did not necessarily hold formal positions of power or prestige in communities but rather served as the connective communication tissue that alerted their peers to what mattered among political events, social issues, and consumer choices.

As we will discuss in this article, solving the public opinion challenge on climate change means defining or framing the complexities of the issue in a way that connects to the specific core values of various publics, but it also means reaching these audiences with the carefully crafted message. This is not an easy task. The great paradox of today's media world is that the American public has greater access to quality information about climate change than at any time in history, yet public concern remains low and citizens remain demobilized. One major reason is the problem of choice: Citizens select media content not only based on ideology and partisanship but also based on their preference, or lack thereof, for public affairs and science-related information (Prior, 2005). Not only are audiences fragmented and difficult to reach but they are also increasingly distrustful of both news and advertising, preferring instead recommendations from friends, family, coworkers, and peers (Keller \& Berry, 2003).

Survey trends depict the American public for the most part as still largely disengaged from the climate change issue (Nisbet \& Myers, 2007). Various poll analyses reveal that despite Al Gore's Nobel Prize-winning Inconvenient Truth campaign and a record spike in mainstream news attention, a deep partisan divide remains on the topic, with a majority of Republicans continuing to dispute the validity of the science and the urgency of the matter, while also believing that the media has greatly exaggerated the problem (Dunlap, 2008; Pew Research Center for the People and the Press, 2008). Even among Democrats and Independents, a majority of whom say they accept the science and are concerned about global warming, 
the issue still rates as a second- or third-tier political priority (Pew Research Center for the People and the Press, 2008). Other survey research shows that across partisan affiliation, less than a majority of Americans have adopted important personal or household behaviors related to reducing greenhouse emissions or conserving energy (Maibach, Roser-Renouf, \& Taylor, 2008).

Given the lingering perceptual paralysis on climate change-and the likely importance of opinion leaders to break the communication gridlockin this article we synthesize the relevant findings from the several dozen studies on self-designated opinion leadership that have been published over the past five decades. We clarify confusing differences in conceptualization and measurement, provide guidance on how research can be translated into effective climate change communication campaigns, and propose a research and action agenda that can inform future climate change initiatives. Moreover, though our focus in this article is on climate change, we believe our research can serve as a blueprint for using self-designated opinion leaders in campaigns on other science or environmental topics.

In organizing this article as a resource for both scholars and practitioners, we open by reviewing the possible goals and outcomes for a climate change communication campaign. Specific to these goals, drawing on past research, we detail six relevant categories of opinion leaders, discussing methods of identification, and where available, lessons from applications in the areas of politics, public health, and/or marketing. We also review research on message development, coordination, and opinion-leader training. Most of this past research, however, has focused almost entirely on face-to-face interaction; we, therefore, also discuss issues related to the use of social media sites for organizing, as well as the prospects for opinion leadership via digital networks. With this synthesis as a framework, we close the article with an analysis of Al Gore's recruitment of opinion leaders in The Climate Project (TCP) and We campaign, noting the strengths and weaknesses of these initiatives to date.

\section{Goals and Outcomes for Climate Change Campaigns}

Following Maibach, Roser-Renouf, and Taylor (2008), we suggest that there are two major routes through which citizens can directly take action on climate change and to which opinion-leader campaigns can be applied. One path would involve using opinion leaders to promote strong citizen and 
stakeholder demand for policies that will encourage government action, corporate responsibility, and private investments. Examples might include cap and trade emission regimes, carbon and energy taxes, development of alternative energy sources, and changes in community planning.

In this direction, opinion leaders can be used to boost the public's cognitive engagement with the issue of climate change, increasing their knowledge of the scientific and policy details; promoting mobilizing information on how to get involved; generating greater public attention to news coverage and other available information sources; increasing the frequency of public discussion; and altering the perception of climate change as a political priority. Opinion leaders can also be employed to sponsor climate change-specific political participation. Examples include candidate or referendum vote choices or volunteering with an advocacy organization. Finally, opinion leaders can also be used to sponsor civic voice-type activities that communicate to policy makers, institutions, corporations, and other citizens' their concern and policy preferences. Examples include contacting an elected official, writing a letter to the editor of a newspaper, calling in to a radio/television show, posting on a blog, signing a petition, boycotting or "buycotting" a product, or attempting to persuade peers on the issue. (For more on these dimensions of civic engagement, see Zukin, Keeter, Andolina, Jenkins, \& Delli Carpini, 2007.)

The second route would employ opinion leaders in efforts to change personal behaviors and generate consumer demand for products, services, and energy sources that meaningfully reduce greenhouse gas emissions. Examples include increased use of public transportation, less frequent air travel, or a shift in food and dietary habits. Just as importantly, as new energy-efficient or alternative technologies are developed, in order for these products to make a difference, they will require widespread consumer adoption. These products such as hybrid cars or energy-saving appliances are complex, require consumer learning and testing, and can be considered a purchase risk. Past research related to other issues and product categories, however, suggests that these specific kinds of barriers to widespread adoption can be softened by interpersonal influence and the strategic use of opinion leaders (Robertson, Zielinski, \& Ward, 1984).

\section{Who Is an Opinion Leader on Climate Change?}

Over the past decade, advertising managers, political operatives, and marketers have rediscovered the concept of opinion leadership, as popular 
magazine articles and best-selling books such as The Tipping Point (Gladwell, 2002), The Anatomy of Buzz (Rosen, 2002), and Applebee's America (Sosnick, Dowd, \& Fournier, 2006) describe how to take advantage of "mavens," "connectors," "navigators," "network hubs," and "buzz marketing" to sell products and win elections. Yet while marketing professionals are actively targeting opinion leaders, scholarship remains strangely disconnected from these industry trends. In reviewing this literature, there are several major themes that scholars generally agree upon, which should inform climate change communication initiatives.

First, across categories of opinion leaders, there are important shared traits and behaviors that can be divided into a few dimensions (Katz, 1957):

Who one is-This includes certain personality characteristics or values held by the individual;

What one knows-This includes the degree of knowledge and expertise that one has about a particular issue or product; and

Whom one knows-This includes the number of contacts one has as part of their circle of friends and acquaintances.

As a combination of these traits and behaviors, opinion leaders not only help draw the attention of others to a particular issue, product, or behavior but also, perhaps most importantly, signal how others should in turn respond or act. This influence may occur by giving advice and recommendations, by serving as a role model that others can imitate, by persuading or convincing others, or by way of contagion, a process where ideas or behaviors are spread with the initiator and the recipient unaware of any intentional attempt at influence (Weimann, 1994).

In the rest of this section, we review several previously developed definitions and measures of self-designated opinion leadership that are likely to be useful to climate change-related communication campaigns, depending on the goals of the initiative. We also detail the types of strategies that might recruit these individuals into action.

The various categories of opinion leaders reviewed are often distinguished in past research by the survey scales used to identify them. Where relevant, these scales and indices are listed in the appendix by the order they are reviewed. Although self-designated survey scales are perhaps the least expensive and the easiest way for organizations to identify opinion leaders, their shortcoming is that respondents may overestimate or underestimate the actual degree of influence they have in their communication network. Other methods of identification, each with their own drawbacks, include key informant analysis where members of a specific social context are 
asked to rate who they consider to be influential; sociometric analysis where the information giving and seeking connections within a small group is visually mapped; and observational methods that involve an investigator directly recording patterns of communication and behavior among individuals in a small group (see Kim, 2007; Schenk \& Döbler, 2002; Weimann, 1994 for reviews). Ideally, it is best to use a combination of methods in order to effectively capture a valid sample of the opinion leaders within a particular communication context or targeted population.

\section{Political Mobilization on Climate Change}

In climate change-related campaigns designed to boost citizen political participation, enhance cognitive engagement, or spark greater citizen voice, research points to three relevant categories of self-identified opinion leaders.

Issue-specific opinion leaders. This conceptualization follows chiefly from the original observations of Lazarsfeld, Katz, and colleagues (1948): Opinion leaders have an intense involvement with a specific issue or topic, characterized by greater levels of media attention and issue-specific knowledge. Originally in surveys, opinion leaders were identified by just two self-designating items. However, this scale was later extended to a more robust 7-item scale with each item including five response categories (Childers, 1986; see appendix). Importantly, on climate change, the framing of the issue asked about in this battery of items should vary. As we will discuss in a later section, for some respondents climate change will accurately identify their concern, whereas for other social groups, asking about either "energy," "environmental stewardship," or "conservation" might be more appropriate.

Influence as personality strength. In a second category, Gabriel Weimann and colleagues (2007) define opinion leaders as distinguished by their level of personality strength, a construct "reflecting confidence in leadership roles, their aptitude at shaping others' opinions, and their selfperceived impact on social and political outcomes" (p. 180). Building on earlier research by Elizabeth Noelle-Neumann, Weimann developed the strength of personality scale (PS) to identify what he refers to as influentials, testing and refining the scale's validity in the United States, Germany, Israel, and most recently, South Africa (Weimann, 1991; Weimann, Tustin, van Vuuren, \& Joubert, 2007).

The scale consists of 10 self-assessed survey items (see appendix) and focuses on distinct personality traits that are assumed to be predictive of 
opinion leadership. These traits include confidence, leadership, persuasiveness, and the frequency with which individuals give advice and assume responsibility. In tests of validity comparing the scale to the outcomes of sociometric analysis within small communities, individuals with strong personality were found to be socially connected to a greater number of other community members and more likely to influence the opinions of others (Weimann, 1994).

The influentials' PS scale represents perhaps the most well-developed scale for identifying opinion leaders who are broadly attentive to public affairs. Yet despite the careful research relative to identification our review of the literature and correspondence with Weimann reveals few if any applied campaign uses of the PS scale. However, lessons from other opinionleader categories reviewed in this article do provide models for how the PS scale might similarly be incorporated into campaigns.

Roper ASW's Influentials. Not to be confused with Weimann's work, Roper ASW executives Ed Keller and Jon Berry (2003) synthesize several decades of the firm's research in their top-selling book The Influentials. According to the two executives, as early as the 1940s, firm founder Elmo Roper concluded in a study commissioned by the Standard Oil Company that "Americans who were more politically and socially active . . . appear to be the thought leaders on public affairs" (p. 19). These individuals, according to Roper, would be "most articulate in their feelings about big corporations" and "most concerned to attack or defend them" (p. 18).

Roper ASW uses a 12-item scale in surveys that taps a respondent's levels of political involvement, participation, and opinion expression (see appendix). If an individual answers affirmatively to 3 or more of the 12 items, they are categorized as an opinion leader across domains of public affairs and consumer products. A strength of the Roper ASW scale is that it taps not only political opinion-giving in the form of making speeches, contacting an official, or writing an article, but also the relative size of an individual's social network as measured by associational membership and activity (Nisbet, 2005).

Relevant to climate change, Roper research shows that influentials are substantially more interested in the respective topics of the environment, nature and animals, science, and technology than the rest of the public. Influentials tend to place shared responsibility for solutions on government, business, and community members, and their commitment to the environment extends to the marketplace, with a majority saying they would be willing to pay more for energy efficient cars, appliances, and for electricity generated from renewable resources (Keller \& Berry, 2003). 
In terms of applications, consider how the George W. Bush campaign incorporated a modified version of Roper's opinion-leader identification scheme into its successful 2004 reelection bid. Campaign organizers sent an e-mail questionnaire to their national list of 7 million volunteers, asking 4 specific questions about how willing volunteers were to write letters to the editor, talk to others about politics, forward e-mails, or attend public meetings. Based on answers to these questions, the Bush team segmented out 2 million opinion leaders. Contacted on a weekly basis by e-mail and phone, these 2 million self-designated opinion leaders were asked to talk up the campaign to friends, write letters to the editor, call in to local radio programs, or attend public meetings staying on message at all times with nationally coordinated talking points. These supporters were used as grassroots information brokers, passing on interpersonally to fellow citizens the themes featured in political ads, news coverage, and in presidential stump speeches.

The Bush campaign reinforced their volunteers' commitment by providing personal access to VIPs such as a local Congressman or national campaign spokespeople. "Life-targeting" databases also allowed the campaign to match up their opinion leaders with local voters who shared similar consumer preferences and product tastes, correlates that the campaign would use as proxy measures for predicting the effect of issue-specific appeals. For example, an opinion leader tagged as a terrorism moderate would be asked to call other terrorism moderates living in his or her surrounding county (Sosnik et al., 2006).

\section{Personal Behavior and Consumer Choices on Climate Change}

There are three additional categories of self-designated opinion leaders that can be used to promote environmentally sustainable behaviors and consumer choices related to climate change. Similar to political mobilization, with each category, previous studies indicate specific self-identification scales that should be used. These studies also offer valuable lessons for recruitment and targeting.

Product- or behavior-specific opinion leaders. Childers' (1986) previously mentioned 7-item scale that operationalizes Katz and Lazarsfeld's (1955) original construct can also be adapted to identify individuals who pay closer attention to behaviors and products such as recycling, public transportation, carpooling, dietary choices, household energy use, hybrid cars, or energy efficient appliances (see appendix.)

Communicative early adopters. Closely related to research on selfdesignated opinion leadership is a sizable literature on the "diffusion of 
innovations" (Rogers, 2003). This research focuses on the nature and role of early adopters or innovators in the spread of ideas, products, or technology. Yet early adopters and self-designated opinion leaders exhibit important differences that are relevant to campaigns promoting energy-saving products and technologies. In particular, Venkatraman (1989) drew a distinction between opinion leaders, early adopters, and what she refers to as communicative early adopters. Whereas opinion leaders pass on their evaluations of a product through interpersonal communication with others in their peer group, early adopters exert their influence primarily through nonverbal means, by using a product and simply making it more physically visible to others (Baumgarten, 1975).

Venkatraman (1989) argued that in promoting a new product line or technology such as a hybrid car or energy-efficient appliance, campaign strategists should target individuals at the intersection of opinion-leadership and early adoption, thereby optimizing both physical visibility and positive word-of-mouth. She recommends identifying these communicative early adopters as consumers who score high on both measures of productspecific opinion leadership (as measured by the Childers scale) but also on traditional early adoption scales as developed in the diffusion of innovation literature. We recommend the frequently cited consumer innovativeness index, which measures the predisposition to learn about and adopt new products within a specific consumer domain (Goldsmith \& Hofacker, 1991; see appendix).

Market-mavens. Unique from both opinion leaders and communicative adopters, previous research has identified market mavens as holding expertise and influence in broader marketplace-related information rather than just a type or class of consumer good. Market mavens are enthusiastic advice givers, with studies showing that mavens do not have to be early users or purchasers of a product to pass on information. In lieu of personal product use, a market maven's expertise derives from closer attention to magazines and consumer-focused Web sites. They also exhibit greater participation in activities such as using coupons, recreational shopping, reading advertisements, responding to direct mail, and providing retailers with personal information (Feick \& Price, 1987; Walsh, Gwinner, \& Swanson, 2004). In surveys, market mavens are identified using a 6-item scale first developed by Feick and Price (1987; see appendix).

Market mavens can be valuable targets in climate change-related campaigns promoting new energy-efficient products or consumer technology. Applied to these campaigns, Clark and Goldsmith (2005) recommend 
appealing to several identified personality attributes of market mavens including status and perceived uniqueness. Yet they also warn that market mavens do not want to purchase products that place them too far outside of perceived norms. The implication is that campaign messages and advertising should emphasize the different but still socially acceptable nature of a product, focusing on its newness and status-enhancing attributes.

An example relevant to climate change is the marketing success of Toyota's Prius. In focus groups, prospective hybrid buyers say they believe that driving a distinctively shaped Prius sends a conspicuous signal about values, a message that respondents expect to generate acclaim from peers. As auto manufacturers continue to introduce hybrid versions of their traditional models, they are now careful to let "buyers broadcast their earth-friendliness" by way of 3-inch hybrid labels, and/or unique grille, wheels, or tail lights (Brand Neutral, 2006; Kerwin, 2003; Schneider, 2004).

In general, mavens talk significantly more about campaigns and sales at stores, and pay closer attention to advertising and special offers (Higie, Feick, \& Price, 1987). Research also shows that market mavens are motivated psychologically by a sense of duty to pass on product information, by a sense of pleasure they derive from doing so, and by a desire to appear as a "competent helper" to friends and peers. On climate change, this research suggests that advertising to mavens should emphasize appeals such as "Now that you know how [energy-saving product] work, you have a duty to tell others." Additionally, stores should make it easy for mavens to enjoy spreading the word about sustainable products, adding social media features to a campaign and creating rewards such as bonus points when mavens get others to purchase a product (Walsh, Gwinner, \& Swanson, 2004). Overall, market mavens hold important implications for big-box store chains such as Wal-Mart that have set "green" campaign goals that include selling fluorescent light bulbs and other energysaving products. In reaching mass consumers, market mavens are likely to be the central go-betweens for these stores.

\section{Message Development and Coordination}

In opinion-leader campaigns on climate change, identification is just the first stage of organizing. Messages need to be tailored to core ideas and values that resonate with the social background of the opinion leader. Moreover, the opinion leader needs to be trained in how to deliver these messages to their social network. For many members of the public, a complex and contested issue such as climate change can be the ultimate ambiguous threat, meaning 
that depending on how the problem is framed, the public will pay more attention to certain dimensions or considerations of global warming over others. These framed messages lead to very specific attributions about the nature and personal relevance of climate change, who or what might be responsible for the problem, and what should be done in terms of policy, political activity, or personal behavior (Nisbet, 2009; Nisbet \& Mooney, 2007; Nisbet, Scheufele, 2001).

In other words, activating concern and catalyzing behavior change across key segments of the public depends on establishing the right perceptual context. The communication challenge is to shift climate change from the mental box of "uncertain science," an "unfair economic burden," or a "Pandora's box" of disaster toward a new cognitive reference point that connects to something the specific intended audience already values or understands. As recent examples, several campaigns recast climate change as an opportunity to grow the economy through the development of clean-energy technology or the creation of "green-collar jobs;" other campaigns redefine climate change as a matter of public health or moral and religious duty. Campaign organizers need to draw on focus groups, in-depth interviews, experiments, and surveys to identify and test different frames across population segments or relative to a targeted specialized audience. These messages can then be placed in climate change media campaigns and matched to opinion leaders for interpersonal or online dissemination (Maibach, Roser-Renouf, \& Taylor, 2008; Nisbet, 2009).

When surges in communication and public attention are needed-such as surrounding the release of a future IPCC report or a vote in Congressopinion leaders can be activated with talking points to share in conversations with friends and coworkers, in e-mails, in blog posts, or letters to the editor. Much like the Bush campaign did in 2004, interpersonal messages would then resonate with the available news media interpretations. In similar fashion, networks of opinion leaders can be activated in reaction to major natural disasters and focusing events such as hurricanes, wildfires, and extreme weather. Audience surveys indicate that these events are among the most followed news items of the year, and given the heavy public attention and interest, stand as untapped mobilizing opportunities.

\section{Training and Retention}

In a series of studies evaluating the use of opinion leaders in HIV prevention programs, Jeffrey Kelly and his colleagues (Kelly, 2004; Kelly et al., 1991) used key informants to identify influentials among gay men, yet his 
subsequent findings on effective methods for training and retention are directly applicable to climate change-related opinion-leader campaigns utilizing self-designated techniques. First, Kelly emphasizes that the activities of opinion leaders need to be programmatically reviewed, supported, and sustained over time. Specifically, regular reunions or booster sessions of opinion-leader cohorts should be used to reinforce training and to maintain volunteer enthusiasm. Between reunions, opinion leaders should set goals for themselves, such as number of contacts, in order to forge a sense of purpose and keep track of their progress. Second, opinion leaders should be trained not as educators disseminating information about climate change, but as communication strategists initiating conversations with friends and acquaintances, deliberately framing messages in ways that make them more meaningful and persuasive to their recipients. For instance, Kelly suggests that opinion leaders should specifically emphasize a desired behavior change- such as using public transportation to travel to work-emphasizing the benefits and advantages of the behavior; recommending practical ways to enact the behavior; and personally endorsing the behavior as something they are already doing. Third, during training, opinion leaders should be introduced to audience research that informs successful messages about climate change; be provided examples of these conversational messages; shown by trainers models of how conversations might play out; and be asked to extensively role play different types of conversational situations, reviewing video of their interactions.

\section{Digitally Networked Climate Leaders?}

With few exceptions, the concept of opinion leadership has been investigated in the context of traditional forms of community and social interaction. In this traditional view, individuals sharing geographical space engage in predominantly face-to-face communication, discussing politics, consumer products, or behaviors. Yet in today's networked society, personal interaction is no longer dominated by shared physical proximity, relatively strong ties, and face-to-face conversation but instead by geography-spanning digital interactions that involve many loose ties (Boase, Horrigan, Wellman, $\&$ Rainie, 2006). Under these conditions, opinion-leader influence may either be diminished or potentially enhanced, depending on the context and nature of a campaign.

For example, when individuals switch from face-to-face conversations about climate change to sending personal e-mails or forwarding recommendations, one possibility is that opinion-leader influence may be impaired 
by fewer trust-building and persuasion-enhancing social cues. The ability to send mass e-mails or invitations by way of social networking sites, efficiently activating many loose ties at once, may suffer from a quality of interaction, and may be no more effective than passing out flyers to strangers. Moreover, past research suggests that online recommendations about products or climate change-related behaviors will be strongly filtered by an individual's relevant experience as well as their offline interpersonal sources. In fact, studies show that face-to-face recommendations are still overwhelmingly preferred over digital sources of information (Berry \& Keller, 2006; Carl, 2006; Xue \& Phelps, 2004).

An alternative possibility is that digital networks would not necessarily displace face-to-face opinion leader activities on climate change but rather serve as a way to enhance such influence, with real-world encounters facilitated and strengthened by electronic interactions. For example, new and still developing technologies such as instant messaging, texting, blogs, and RSS feeds can help cut down on e-mail clutter and allow users to potentially consume information about climate change at their preferred pace. Web sites such as MySpace and Facebook have built in online communities of millions of users, with opinion leaders already existing and at work within these digital environs, offering the potential for the sharing and posting of pictures and videos that offer important climate change-related visual information and cues. Moreover, digital networks are not just for the channeling and forwarding of messages, but they can also be used to directly deliver products, money, volunteer action, and staff coordination across geographic and time boundaries (Rosenblatt, 2007).

Relevant applications and lessons for climate change initiatives can be taken from the digital organizing strategies used by the Barack Obama presidential campaign. Launched in 2007, the My.BarackObama.com platform is a Facebook-like site that not only helps the campaign communicate with supporters and raise money, but it is also designed to help supporters connect with one another, organizing events in their local community. Perhaps the most innovative strategy for combining digital tools and face-to-face opinion leadership was the campaign's creation of an Obama iPhone application. The interface organized friends and contacts by key battleground states, encouraged users to call their friends on behalf of Obama; provided information on local events; and included videos and issue backgrounders that users could reference during face-to-face conversations with friends. The application also provides feedback data to the campaign, such as the number of phone calls successfully completed (Shankland, 2008). 
Bloggers as opinion-leaders. Recent survey research also suggests that bloggers, across issue areas, hold strong opinion-leader-like traits and, therefore, should be targeted and used as resources in climate change campaigns. Some bloggers might be defined as agitators, sparking discussion and attention about climate change-related events whereas others might be better categorized as synthesizers, compiling and making sense of news, scientific reports, and other blog material. In comparison to other Internet users, bloggers generally are stronger consumers of online news and earlier adopters of content creation and sharing technologies such as YouTube. They are also more digitally embedded than other Internet users, with surveys showing that they are more frequent users of features such as instant messaging, text messaging, comments, blogrolls, friends lists, and RSS feeds; tools which facilitate more connectedness and recommendations (Pew Internet and American Life Project, 2006). Bloggers can not only help set their readers' agenda on climate change but the media agenda as well, engaging in a digitally enhanced multistep flow of agenda setting (Brosius \& Weimann, 1996). Climate change-related organizations can engage with bloggers using techniques similar to the cultivation of journalists, developing personal relationships while also providing bloggers with content pitches that fit easily into their posts and that match their reader preferences and interests.

\section{The Climate Project and the "We" Campaign}

Given their prominence, two recent communication campaigns launched by former vice president $\mathrm{Al}$ Gore are likely to serve as models for future opinion-leader campaigns, and therefore, their details are worth evaluating. Following the release of An Inconvenient Truth, in mid-2006 Gore launched TCP, an initiative that has trained more than a 1,000 volunteers to present a version of Gore's slideshow presentation to local organizations and groups. In the spring of 2008, Gore followed with the We campaign, an initiative that transcends TCP in resources and goals, combining many of the strategies reviewed in this article so far, including reframing the issue around shared values; using digital technology to enhance opinion-leadership; and coordinating opinion leaders with key focusing events, paid advertisements, or news media strategies. To gather information on these twin initiatives, we reviewed campaign materials and Web sites, relied on news reports about the campaigns, and interviewed Jenny Clad, Director of TCP.

$T C P$. Admitting little previous knowledge of the research in the area, organizers of TCP relied on a self-selection model to identify and recruit 
opinion leaders. A call for volunteers was placed on TCP's Web site and interested individuals filled out an application form that asked people to rate their experience as a presenter, their public-speaking ability, their level of comfort with speaking in front of large audiences, and their existing expertise in environmental and climate change issues. Additionally, where possible, applicants were selected based on geographic location and social background. Moreover, in order to ensure that the slideshow's message would cut across social groups, applicants were asked to name five venues in which they would likely give the presentation.

By April 2007, an initial pool of 1,000 volunteers had been personally trained by $\mathrm{Al}$ Gore. The personal connection with Gore was intended to help motivate speakers to attain their requisite goal of giving a minimum of 10 presentations in their first year. Trainees were encouraged to tailor the slideshow to fit with their intended audiences, as long as the general message and flow of the slideshow was preserved. Presentations, for example, have been customized for business leaders, church groups, and elementary school classrooms. To date, the explicit goals of TCP have been solely focused on educating the public about climate change and generating greater citizen concern. TCP has not officially endorsed the adoption of any particular set of behaviors or policies, pending the completion of a June 2009 book on the topic by Gore.

Although trainees are allowed to include slides that provide suggestions for ways in which individuals can take personal action to solve the problems of global warming, TCP does not provide an official list of solutions to speakers. Moreover, while presenters are permitted to suggest behavior changes such as using compact fluorescent light bulbs, taking shorter showers, and riding bikes, they are discouraged from advocating specific candidates for political office because of the organization's tax-exempt status.

After the initial training sessions with Gore, participants were given access to a secure log-in section of TCP Web site where they could share experiences, discuss challenges that they have encountered, and exchange new slides that may be useful for engaging specific audiences. Not only is the site intended to create a sense of community and purpose among participants, it also provides a forum where they can receive additional instruction and advice from their peers about how to improve the presentation. Weekly e-mail newsletters also provide speakers with encouragement as well as updated information to incorporate into the slideshows. For a large-scale campaign such as TCP, this is a cost-effective, efficient way to aid presenters without spending the extra time and resources necessary for additional face-to-face 
training sessions. Since its inception in 2006, Gore has also trained hundreds of individuals in other countries, including Australia, Canada, India, Spain, and the United Kingdom. Today, the total number of TCP presenters worldwide is estimated by the organization to be over 2000 individuals, with more than 10,000 presentations given, and an estimated combined audience of over 1 million people.

The We campaign. Launched in April 2008, the We campaign plans to spend $\$ 300$ million dollars over 3 years to recruit 10 million activists on climate change. The campaign's explicit goal is to create public opinion pressure on elected officials to adopt major policy actions. "Elected officials ... are going to be timid about enacting bold changes that are needed until there is a change in the public's sense of urgency in addressing the crisis," Gore told reporters at the campaign's launch (Eilperin, 2008). Gore announced the campaign with an interview on 60 Minutes, via an hour-long conference call with newspaper reporters, and by targeting nonnews audiences with paid advertisements at entertainment programs such as American Idol, in movie theaters, and at magazines such as People. According to Cathy Zoi, We campaign director, the goal is to recruit influentials to be active on climate change, or as she defined them for the New York Times: “ . . people who talk to five times as many people a day as the typical person, who derive self-esteem from having new information" (Revkin, 2008).

Shifting from An Inconvenient Truth's dominant frame of looming disaster, the We campaign refocuses on a bipartisan "moral call to arms" to unify behind solving a collective threat. In television and print advertisements titled "strange bedfellows" and "unlikely alliances," the We campaign attempts to break through partisan perceptions by pairing spokespeople such as Nancy Pelosi and Newt Gingrich or Al Sharpton and Pat Robertson. Other ads compare action on global warming to the storming of the beaches at Normandy, the Civil Rights movement, the Space Race, and the recovery from the Great Depression. Subsequent to the launch of the We campaign, journalists also started to emphasize this new moral framing of climate change, with a much talked about Time magazine cover image morphing the iconic Iwo Jima photograph into environmental soldiers hoisting a pine tree (Nisbet, 2009).

Importantly, most of the paid We advertising directs audiences to visit the campaign Web site, the main platform for putting into action 10 million climate change activists. The major "ask" at the site is for visitors to sign up to be part of the campaign's action e-mail list so that "your voice can be heard." Immediately, for visitors, the most visually prominent feature of the 
site is the pop-up projection of a video of a volunteer presenter from Gore's TCP, telling visitors in his or her own words why they need to get involved and/or explaining a feature of the site. Also prominent on the front page of the site is statistical information on the 1.5 million people to date who want to be part of the solution on climate change.

Similar to My.BarackObama.com, the We site features a social networking component like Facebook, where visitors can create a profile, befriend other people, write blog entries and letters to the editor, create groups, and attempt to organize local events in their community. From observation of the e-mails that have been sent out by the campaign since its launch, many of these action alerts have been coordinated with either a major vote in Congress, a major speech by Gore, or, for example, the launch of a new commercial during the August 2008 Olympics broadcast. As an incentive for contacting other citizens, if participants through word of mouth, forwarded e-mails, and/or other social media actions successfully encouraged 40 friends to also sign up, they would be named a "We leader" and have "access to special information." The We campaign also launched its own Facebook application, where participants (referred to as Climate Champions) who signed up fellow Facebook friends could earn points that donors would then match as financial contributions to the campaign.

As of early August 2008, there were roughly 16,000 Climate Champions on Facebook, who had collectively raised a total of $\$ 5,878$. The second author of this article, who had earned 6 points through his participation, (a total of 60 cents from donors), ranked among the top $10 \%$ of point earners, suggesting that just a few individuals had been active in accumulating most of the new friends for the application. Moreover, according to Facebook, the top two Climate Champions were from outside of the United States, with the top earner having raised $\$ 1,100$ dollars or roughly $20 \%$ of the total.

The We campaign also has a special section for bloggers to download "We" logos or embed advertisements and videos as well as an RSS feed with campaign-related press releases. The site asks bloggers to fill out a short questionnaire so that the campaign can track the audience size for the blog, the blog's content focus, and the ideological orientation of the blogger. Other features of the site have asked visitors to donate money so that the campaign can purchase a full-page advertisement in the New York Times, has asked visitors to vote to see who else they would like to appear in a future unlikely bedfellows ad, and has sponsored a contest for the best independently produced advertisement. 


\section{Conclusion}

As we have reviewed, previous research in the areas of politics, public heath, and marketing identify several different conceptualizations and measures of opinion leadership. Although these different categories of self-designated opinion leaders share several core traits and behaviors, the specific opinion leader targeted in a climate change-related campaign should depend on the communication goal and the population. With this in mind, our focus in this article has been to introduce a toolbox of concepts, measures, and strategies for use in climate change-related campaigns. We do not suggest that opinionleader campaigns should replace more traditional grassroots activities or media strategies, but rather we argue that opinion leaders are an overlooked complement to these efforts.

We have grouped relevant past research into two main areas: (1) those studies more relevant to political mobilization, and (2) the work more specific to personal behaviors and consumer choices. While we feel confident in highlighting these categories of opinion leaders as the most relevant to climate change campaigns, our review also suggests several salient issues and questions that need to be addressed by both scholars and practitioners.

Identification, recruitment, and training. In this article, we focus on identification of opinion leaders by way of survey-based self-designation, detailing the relevant measures in the appendix. The self-designated method is perhaps best suited for a cost-effective communication campaign at the national or regional level or a campaign utilizing e-mail, the Web, or a social media site. When possible, the validity of these scales can be further developed by triangulating their results with sociometric and peer-identification measures employed at the community level (see Weimann, 1994).

Although there has been extensive scholarly research on identification methods, there is far less work on the types of appeals and incentives that might recruit opinion leaders into action and then how to best train and retain them. At times, opinion intensity and emotional commitment to the campaign may serve as sufficient motivation, with requests to get involved from a campaign serving as a natural outlet for the opinion leader. Yet as several studies and examples suggest even these committed volunteers likely require contacts with VIPs, special access to information, or even a bonus and rewards point system to stay involved. Moreover, research on communicative adopters and market mavens suggests studying the psychological profile of opinion leaders for clues as to what kinds of appeals and incentives might trigger and maintain their involvement. Few, if any, studies 
have been as rigorous in directly evaluating training and retention strategies as the public health work by Kelly and colleagues (1992), and we suggest that this work might be a model for climate change initiatives.

Message coordination matters. It is not enough to recruit an opinion leader on climate change, they also need to be trained to deliver a specific message. This includes introducing opinion leaders to the research that went in to designing the message along with extensive role playing for how that message might be delivered across face-to-face contacts. In particular, when possible, carefully framed messages about climate change should be matched to an opinion leaders' demographic using micro-targeting data, cluster analysis, or other market segmentation techniques. There is also the challenge of adapting these framed messages for purposes of either face-to-face dissemination or digital delivery by way of e-mail or social media sites.

The promise of digital opinion leaders? With Gore's initiative as a model, future climate communication campaigns are likely to make online organizing a central feature of their efforts. Indeed, digital opinion-leader campaigns may be especially appealing because of the relative ease in which organizers can develop metrics to measure success. Yet ease in tracking data does not equate to effectiveness, and we urge caution in overrelying on digital networks, especially in place of face-to-face influence. Surveys show that Americans prefer their recommendations via verbal interaction and there still does not exist strong research on whether or not the self-selection biases of the Web can be overcome within these digital networks. Moreover, to date, by all accounts the success of the digital organizing efforts of the We campaign have been relatively modest at best.

With strong selectivity bias online, digital interaction might simply result in ideological reinforcement and intensification of beliefs about climate change, which may eventually limit the willingness of recruited opinion leaders to compromise on pragmatic policy solutions (a typical social movement problem perhaps amplified by the Web). Moreover, if the weak ties of digital interactions lack the strength of traditional opinion-leader influence, then time and effort spent online by digital opinion leaders may be far less effective than traditional face-to-face influence. The danger of relying too heavily on digital organizing is that it might create a false sense of efficacy among participants, with activists believing they are making a difference on climate change, when impact may be limited at best. Given these many dimensions of online influence, the goal for both researchers 
and practitioners is to figure out under what conditions or with which demographic segments digital opinion leaders can be effectively used on climate change, and in which ways can online interactions build on realworld ties. Combining digital organizing with face-to-face interaction by using handheld devices such as the iPhone, as was done in the Obama campaign, is a strategy that future climate change efforts should explore.

Translation, evaluation, and transparency. All of these issues suggest the need for more research and evaluation of self-identified opinion-leader campaigns. As Katz (1994) noted more than a decade ago, scholars continue to be overly preoccupied with the development of opinion-leader scales or other methods of identification. As a result, there has been far less focus on translating and applying research to actual campaigns, and/or to evaluating the effectiveness of these campaigns. Yet this blind spot means that researchers are missing out on opportunities to engage in theory development while also gaining sources of funding and showing the value of communication research to help solve important societal problems such as climate change. (For example, Lazarsfeld's original work on opinion leaders was a direct result of this synergy among theory development, campaign evaluation, and applied work.)

On the practitioner side, as scholars turn to translating their work, campaigns need to be more scientific in drawing upon this research, while also carefully evaluating their impact and effectiveness. For example, Gore's TCP was launched with scant awareness of past research on opinion leaders. Obviously, the sophistication of opinion-leader campaigns and their evaluation will depend on budget, staff time, and available resources. With this in mind, researchers and practitioners need to work together to develop scalable methods and strategies and then to share these methods with others. Scholars can also work with practitioners to develop metrics for assessing campaign impact, data that will be valuable for gaining and maintaining support from various funders.

Questions of ethics and norms. Finally, using opinion leaders in public communication campaigns introduces several issues related to ethics and norms. First, opinion-leader campaigns raise general questions about privacy, especially when campaigns are coordinated using micro-targeting or other market segmentation strategies. As a general rule, opinion leaders should disclose their efforts on the part of a campaign, and organizers should follow closely the most rigorous ethical standards in their use of evermore personalized micro-targeting techniques (see Montgomery, 2007, 
for an overview). Moreover, adding climate change to the already sizable number of commercial products, which are the subject of opinion-leader or buzz marketing efforts, might simply add to what some warn is the "commercialization of chit-chat," with citizens growing as distrustful of such situations as they are currently of traditional advertising or the news media (Walker, 2004).

Finally, much like the debate over applying framing research to science issues (Nisbet, 2009), opinion-leader campaigns on climate change raise questions relevant to the traditional communication posture of scientific institutions. Some critics, for example, may fear that when using lay citizens as conversational representatives, science organizations risk losing control of the message about climate change, and spreading scientifically inconsistent information. Yet this fear only underscores the importance of training, follow-up, and monitoring of opinion leaders. Critics will also likely argue that using opinion leaders to pass on information to the public is wrong because it mirrors the types of tactics that climate skeptics have used in the past. But if scientists and their institutions have a duty to study the nature and problems presented by climate change, they also have a responsibility to communicate their conclusions more effectively. Recruiting opinion leaders to participate in a two-step flow of influence about climate change will only help scientific institutions achieve this mission.

\section{Appendix \\ Political Mobilization on Climate Change}

\section{A. Issue-Specific Opinion Leaders}

The scale operationalizes opinion leadership as a continuum using a summated score on the following 7 items (Childers, 1986, p. 186). For identification purposes, campaigns may want to use as a cut point the top $10 \%, 15 \%$, or $25 \%$ of respondents.

Please rate yourself on the following scales relative to your interaction with friends and neighbors regarding. (climate change, global warming, environmental stewardship, energy conservation):

1. In general, do you talk to your friends and neighbors about climate change? $(1=$ never $; 5=$ very often $)$

2. When you talk to your friends and neighbors about climate change, do you $\ldots(1=$ give very little information; $5=$ give a great deal of information) 


\section{Appendix (continued)}

3. During the past 6 months, how many people have you talked to about climate change? $(1=$ told no one; $5=$ told a number of people $)$

4. Compared with your circle of friends, how likely are you to be asked about climate change? $(1=$ not at all likely to be asked; $5=$ very likely to be asked)

5. In a discussion of climate change, would you be most likely to . . . ( $1=$ convince your friends of your ideas; 5 = listen to your friends' ideas)

6. In a discussion of climate change, which of the following happens most often? $(1=$ your friends tell you about climate change $;=$ you tell your friends about climate change)

7. Overall in all of your discussions with friends and neighbors, are you ... $(1=$ not used as a source of advice $; 5=$ often used as a source of advice $)$.

\section{B. Influentials Strength of Personality (PS) Scale}

Respondents are asked to agree or disagree with the following statements (Weimann et al., 2007, p. 179). Answers are combined into a weighted scale. In previous studies, top quartile of respondents on the scale were considered to be influentials (see Weimann, 1991).

1. I usually rely on being successful in everything I do.

2. I am rarely unsure about how I should behave.

3. I like to assume responsibility.

4. I like to take the lead when a group does things together.

5. I enjoy convincing others of my opinions.

6 . I often notice that I serve as a role model for others.

7. I am good at getting what I want.

8. I am often a step ahead of others.

9. I have many things others envy me for.

10. I often give others advice and suggestions.

\section{Roper ASW's Influentials}

Not counting signing a petition, to qualify as an influential, respondents had to have done three or more of the activities on the list (Keller \& Berry, 2003, p. 19).

Here is a list of things some people do about government or politics. Have you happened to have done any of these things in the past year? Which ones?

1. Written to or called any politician at the state, local, or national level.

2. Attended a political rally, speech, or organized protest of any kind. 


\section{Appendix (continued)}

3. Attended a public meeting on town or school affairs.

4. Held or run for political office.

5. Served on a committee for some local organization.

6. Served as an officer for some club or organization.

7. Written a letter to the editor of a newspaper or magazine or called a live radio or TV show to express an opinion.

8. Signed a petition. ${ }^{\mathrm{a}}$

9. Worked for a political party.

10. Made a speech.

11. Written an article for a magazine or newspaper.

12. Been an active member of any group that tries to influence public policy or government.

a. Not included in scores for respondents, used to test for social desirability.

\section{Personal Behavior and Consumer Choices on Climate Change}

\section{Product- or Behavior-Specific Opinion Leaders}

The previous reviewed questions in the scale developed by Childers (1986) (see Appendix "A") should be adapted to be specific to a category of product or type of behavior. The introduction to these questions can read:

Please rate yourself on the following scales relative to your interaction with friends and neighbors regarding (use of public transportation, using energy-efficient household products, cutting back on energy use in your daily life, ect.):

\section{E. Communicative Adopter}

Venkatraman recommends combining Childer's 7-item opinion-leader scale with a measure of consumer domain innovativeness (Goldsmith \& Hofacker, 1991, p. 212; Venkatraman, 1989, p. 60). These scales would be tailored to the specific domain of consumer good or product such as energy-saving household appliances, hybrid cars, and so on. As a domain-specific-consumer innovativeness measure, Goldsmith and Hofacker's (1991) scale is widely recognized in the marketing literature.

In this measure, on a 7-point response scale, respondents are asked to agree or disagree with the following statements:

1. In general, I am among the first in my circle of friends to buy a new (energy-efficient product, green product, fuel-efficient car, etc.) when it appears. 


\section{Appendix (continued)}

2. If I heard that a new (energy-efficient product, green product, fuel-efficient car, etc.) was available in the store, I would be interested enough to buy it.

3. Compared to my friends, I own a lot of (energy-efficient products, green products, an fuel-efficient car, etc.).

4. In general, I am the first among my circle of friends to know about a new (energy-efficient product, green product, fuel-efficient car, etc.).

5. I know the names of new (energy-efficient products, green products, fuel-efficient cars, etc.) before others do.

\section{F. Market Mavens}

Mavenship is measured on a continuum as the additive index of scores on the 6 items listed below (Feick \& Price, 1987, p. 95). Campaigns are recommended to choose the top $10 \%, 15 \%$, or $25 \%$ cut points for identification purposes. Questions are administered on a 7-point, strongly agree/strongly disagree scale.

1. I like introducing new brands and products to my friends.

2. I like helping people by providing them with information about many kinds of products.

3. People ask me for information about products, places to shop, or sales.

4. If someone asked where to get the best buy on several types of products, I could tell him or her where to shop.

5. My friends think of me as a good source of information when it comes to new products or sales.

6. Think about a person who has information about a variety of products and likes to share information with others. This person knows about new products, sales, stores, and so on, but does not necessarily feel he or she is an expert on one particular product. How well would you say that this description fits you?

\section{References}

Baumgarten, S. A. (1975). The innovative communicator in the diffusion process. Journal of Marketing Research, 2, 12-18.

Berry, J. L., \& Keller, J. A. (2006). "Spoken Word-of-Mouth, the Most Effective Medium," Presentation at the Word of Mouth Marketing Summit \& Research Symposium, Washington, DC.

Boase, J., Horrigan, J. B., Wellman, B., \& Rainie, L. (2006). The strength of Internet ties. Pew Internet and Public Life Project. Retrieved November 24, 2008, from http://www .pewinternet.org/PPF/r/172/report_display.asp

Brand Neutral. (2006). The Prius Effect. Retrieved November 24, 2008, from http://www .brandneutral.com/documents/Prius_Effect.pdf 
Brosius, H., \& Weimann, G. (1996). Who sets the agenda? Agenda-setting as a two-step flow. Communication Research, 23, 561-580.

Carl, W. J. (2006). What's all the buzz about? Everyday communication and the relational basis of word-of-mouth and buzz marketing practices. Management Communication Quarterly, 19, 601-634.

Childers, T. L. (1986). Assessment of the psychometric properties of an opinion leadership scale. Journal of Marketing Research, 23, 184-188.

Clark, R. A., \& Goldsmith, R. E. (2005). Market mavens: Psychological influences. Psychology and Marketing, 22, 289-312.

Dunlap, R. E. (2008, May 29). Climate-change views: Republican-Democratic gaps expand. Gallup News Service. Retrieved November 24, 2008, from http://www.gallup.com/poll/ 107569/ClimateChange-Views-RepublicanDemocratic-Gaps-Expand.aspx

Eilperin, J. (2008, March 31). Gore launches ambitious advocacy campaign on climate. The Washington Post. Retrieved November 24, 2008, from http://www.washingtonpost.com/ wp-dyn/content/story/2008/03/30/ST2008033002195.html?sid=ST2008033002195

Feick, L. F., \& Price, L. L. (1987). The Market maven: A diffuser of marketplace information. Journal of Marketing, 51(1), 83-97.

Gladwell, M. (2002). The tipping point. New York: Time Warner.

Goldsmith, R. E., \& Hofacker, C. F. (1991). Measuring consumer innovativeness. Journal of the Academy of Marketing Science, 19, 209-221.

Higie, R. A., Feick, L. F., \& Price, L. L. (1987). Types and amount of word-of-mouth communications about retailers. Journal of Retailing, 63, 260-278.

Katz, E. (1957). The two-step flow of communication: An up-to-date report on an hypothesis. Public Opinion Quarterly, 21, 61-78.

Katz, E. (1994). Forward. In G. Weimann, The Influentials: People who influence people (pp. ix-xiii). Albany:State University of New York Press.

Katz, E., \& Lazarsfeld, P. F. (1955). Personal influence: The part played by people in the flow of mass communication. Glencoe, IL: Free Press.

Keller, E. B., \& Berry, J. L. (2003). The influentials: One American in ten tells the other nine how to vote, where to eat, and what to buy. New York: Simon \& Schuster.

Kelly, J. A. (2004). Popular opinion leaders and HIV prevention peer education: Resolving discrepant findings, and implications for the development of effective community programmes. AIDS Care, 17, 139-150.

Kelly, J. A., St. Lawrence, J. S., Stevenson, L. Y., Hauth, A. C., Kalichman, S. C., Diaz, Y. E., et al. (1991). HIV risk behavior reduction following intervention with key opinion leaders of a population: An experimental analysis. American Journal of Public Health, 81, 168-171.

Kelly, J. A., St. Lawrence, J. S., Stevenson, L. Y., Hauth, A. C., Kalichman, S. C., Diaz, Y. E., et al. (1992). Community AIDS/HIV risk reduction: The effects of endorsements by popular people in three cities. American Journal of Public Health, 82, 1483-1489.

Kerwin, K. (2003, February 17). Hybrids: How Detroit can gun the engines. Business Week. Retrieved November 24, 2008, from http://www.businessweek.com/magazine/content/ 03_07/b3820096.htm

Kim, D. K. (2007). Identifying opinion leaders by using social network analysis: A synthesis of opinion leadership data collection methods and instruments. Unpublished dissertation, Ohio University, Athens.

Lazarsfeld, P. F., Berelson, B. R., \& Gaudet, H. (1948). The people's choice: How the voter makes up his mind in a presidential campaign. New York: Duell, Sloan \& Pierce. 
Maibach, E. W., Roser-Renouf, C., \& Taylor, M. (2008). What are Americans thinking and doing about global warming: Results of a national household survey. Fairfax, VA: George Mason University. Available from http://climatechange.gmu.edu

Maibach, E. W., Roser-Renouf, C., \& Leiserowitz, A. (2008). Communication and marketing as climate change intervention assets: A public health perspective. American Journal of Preventive Medicine, 35, 488-500.

Montgomery, K. C. (2007). Generation digital: Politics, commerce, and childhood in the age of the Internet. Cambridge, MA: MIT Press.

Nisbet, E. C. (2005). The engagement model of opinion leadership: Testing validity within a European context. International Journal of Public Opinion Research, 18(1), 1-27.

Nisbet, M. C. (2009). Framing science: A new paradigm in public engagement. In L. Kahlor \& P. Stout (Eds.), Understanding Science: New Agendas in Science Communication. New York: Taylor \& Francis.

Nisbet, M. C., \& Mooney, C. (2007). Policy forum: Framing science. Science, 316(5821), 56.

Nisbet, M. C., \& Myers, T. (2007). Twenty years of public opinion about global warming. Public Opinion Quarterly, 71, 444-470.

Nisbet, M. C., \& Scheufele, D. A. (2007, October). The future of public engagement. Scientist, 21(10), 38-44.

Pew Internet and American Life Project. (2006). Bloggers: A portrait of the Internet's new storytellers. Retrieved November 24, 2008, from http://www.pewinternet.org/pdfs/PIP\% 20Bloggers\%20Report\%20July\%2019\%202006.pdf

Pew Research Center for the People and the Press. (2008). A deeper partisan divide on global warming. Retrieved November 24, 2008, from http://people-press.org/report/417/ a-deeper-partisan-divide-over-global-warming

Prior, M. (2005). News v. entertainment: How increasing media choice widens gaps in political knowledge and turnout. American Journal of Political Science, 49, 577.

Revkin, A. (2008, March 31). Gore group plans ad blitz on global warming. The New York Times. Retrieved November 24, 2008, from http://www.nytimes.com/2008/04/01/business/ media/01green.html?ref=science

Robertson, T. S., Zielinski, J., \& Ward, S. (1984). Consumer behavior. Glenview, IL: Scott, Foresman.

Rogers, E. M. (2003). The diffusion of innovations (5th ed.). New York: Free Press.

Rosen, E. (2002). The anatomy of buzz. New York: Doubleday.

Rosenblatt, A. (2007). In C. Darr \& J. Graff (Eds.), Poli-influentials: The new political kingmakers. Report by the Graduate School of Political Management, George Washington University, Washington, DC.

Schenk, M., \& Döbler, T. (2002). Towards a theory of campaigns: The role of opinion-leaders. In H. Klingerman \& A. Rommele (Eds.), Public information campaigns \& opinion research (pp. 37-51). London: Sage.

Schneider, G. (2004, August 23). Toyota's prius proving to be the hotter ride in hybrids. The Washington Post. Retrieved November 24, 2008, from http://www.washingtonpost.com/ wp-dyn/articles/A24832-2004Aug22.html

Shankland, S. (2008, October 2). Obama releases iPhone recruiting, campaign tool. CNET news. Retrieved November 24, 2008, from http://news.cnet.com/8301-13578_3-10056519-38.html

Sosnik, D. B., Dowd, M. J., \& Fournier, R. (2006). Applebee's America: How successful political, business, and religious leaders connect with the new American community. New York: Simon \& Schuster. 
Venkatraman, M. P. (1989). Opinion leaders, adopters, and communicative adopters: A role analysis. Psychology and Marketing, 6(1), 51-68.

Walker, R. (2004, December 5). The hidden (in plain sight) persuaders. The New York Times. Retrieved November 24, 2008, from http://www.nytimes.com/2004/12/05/magazine/ 05BUZZ.html

Walsh, G., Gwinner, K. P., \& Swanson, S. R. (2004). What makes mavens tick? Exploring the motives of market mavens' initiation of information diffusion. Journal of Consumer Marketing, 21(2/3), 109-122.

Weimann, G. (1991). The influentials: Back to the concept of opinion leaders? Public Opinion Quarterly, 55, 267-279.

Weimann, G. (1994). The influentials. People who influence people. Albany: State University of New York Press.

Weimann, G., Tustin, D. H., van Vuuren, D., \& Joubert, J. P. R. (2007). Looking for opinion leaders: Traditional vs. modern measures in traditional societies. International Journal of Public Opinion Research, 19, 173-190.

Xue, F., \& Phelps, J. E. (2004). Internet-facilitated consumer-to-consumer communication: The moderating role of receiver characteristics. International Journal of Internet Marketing and Advertising, 1(2), 121-136.

Zukin, C., Keeter, S., Andolina, M., Jenkins, K., \& Delli Carpini, M. X. (2007). A new engagement? New York: Oxford University Press.

Matthew C. Nisbet, $\mathrm{PhD}$ (Cornell University), is an assistant professor in the School of Communication at American University, Washington, D.C., where he studies strategic communication in policy making and public affairs, examining controversies surrounding science, the environment, and public health.

John E. Kotcher, MS (American University), is a communications officer at The National Academies, Washington, D.C. 